\title{
Player-Tracking Technology: Half-Full or Half-Empty Glass?
}

\author{
Martin Buchheit and Ben Michael Simpson
}

\begin{abstract}
With the ongoing development of microtechnology, player tracking has become one of the most important components of load monitoring in team sports. The 3 main objectives of player tracking are better understanding of practice (provide an objective, a posteriori evaluation of external load and locomotor demands of any given session or match), optimization of training-load patterns at the team level, and decision making on individual players' training programs to improve performance and prevent injuries (eg, top-up training vs unloading sequences, return to play progression). This paper discusses the basics of a simple tracking approach and the need to integrate multiple systems. The limitations of some of the most used variables in the field (including metabolic-power measures) are debated, and innovative and potentially new powerful variables are presented. The foundations of a successful player-monitoring system are probably laid on the pitch first, in the way practitioners collect their own tracking data, given the limitations of each variable, and how they report and use all this information, rather than in the technology and the variables per se. Overall, the decision to use any tracking technology or new variable should always be considered with a cost/benefit approach (ie, cost, ease of use, portability, manpower/ability to affect the training program).
\end{abstract}

Keywords: global positioning system, semiautomatic video, inertial sensors, accelerometers, load monitoring

With the ongoing development of microtechnology, player tracking has become one of the most important components of load monitoring in team sports. ${ }^{1}$ The scientific literature has grown exponentially over the last decade, and it is very difficult to find an elite team not using the minimum of GPSs, semiautomatic camera or radio-frequency systems, either in isolation or in combination during both training and matches. ${ }^{1}$ The 3 main objectives of player tracking are likely the following: to better understand practices (provide an objective, a posteriori evaluation of external load and locomotor demands of any given session or match), to help with the programming of optimal training load patterns at the team level, and to help with the decision making on individual players' training programs to improve performance and prevent injuries (eg, top-up training vs unloading sequences, return-to-play progression). While such technological advances are of evident value for practitioners and players, limitations in terms of validity and on-field usefulness are still often overlooked. There is also a feeling that people may adopt new technologies and new variables before validity, reliability, and usefulness had been properly evaluated. Early and naïve adopters may often think that technology in itself is a solution, and if they do not use the newest technologies/variables immediately they may fall behind competitors. In fact, most of the time, the introduction of new technologies and monitoring variables adds complexity and slows down systems, rather than improving them. In the present paper, we discuss the basics of a simple tracking approach and the need for the integration of multiple systems. Furthermore, we highlight the limitations of some of the most used variables in the field (including metabolic-power measures) and present some innovative and powerful variables ${ }^{2}$ that may be important in the future.

The authors are with the Performance Dept, Paris Saint-Germain Football Club, Saint-Germain-en-Laye, France. Address author correspondence to Martin Buchheit at mbuchheit@psg.fr.

\section{Integrating Various Systems}

While the precise analysis of each training sequence (drill database ${ }^{3}$ ) is of infinite value for improved training prescription and programming both at the individual and team level, the simple monitoring of players overall external (locomotor) load is probably one of the most important aspects of any monitoring system. ${ }^{1}$ There has been growing evidence to suggest that tracking overall training load accumulation during preseason and/or its acute changes over the time (spikes in load, referring to the so-called training-stress balance or acute-to-chronic load ratio) may be key in better understanding injury risk. ${ }^{4}$ Using the example of soccer (Figure 1), it is not unusual for some players to be tracked by 2 or 3 different systems during the same week. This is likely related to the fact that GPS units, local positioning systems, or radio-frequency-identification sensors are often worn during training sessions, while most teams still use semiautomatic camera systems during official matches. ${ }^{5}$ Since a perfect between-systems agreement in terms of locomotor activity (eg, distance covered, number of accelerations) is problematic, 5 simply providing a cumulative summation of the data gathered by the different systems ${ }^{6}$ is highly hazardous. To allow a proper evaluation of a player's overall locomotor load, and to integrate accordingly the data of different systems, practitioners are recommended to use calibration equations. ${ }^{5}$ Such equations are meant to predict, for example, the running distance that would have been measured with a given system (eg, GPS), while it was actually measured with another one (eg, semiautomatic cameras during a match). While such equations are sometimes provided in the literature from large-scale studies with players tracked simultaneously using different systems under different conditions (eg, training, matches over different pitch sizes), ${ }^{5}$ their usefulness is somewhat limited to the actual systems used to derive those equations; it is therefore advised that practitioners develop their equations using their own systems. It is also important that practitioners readjust these equations when updates in their technology occur. ${ }^{7}$ The most relevant variables to integrate will be discussed in the following section. 


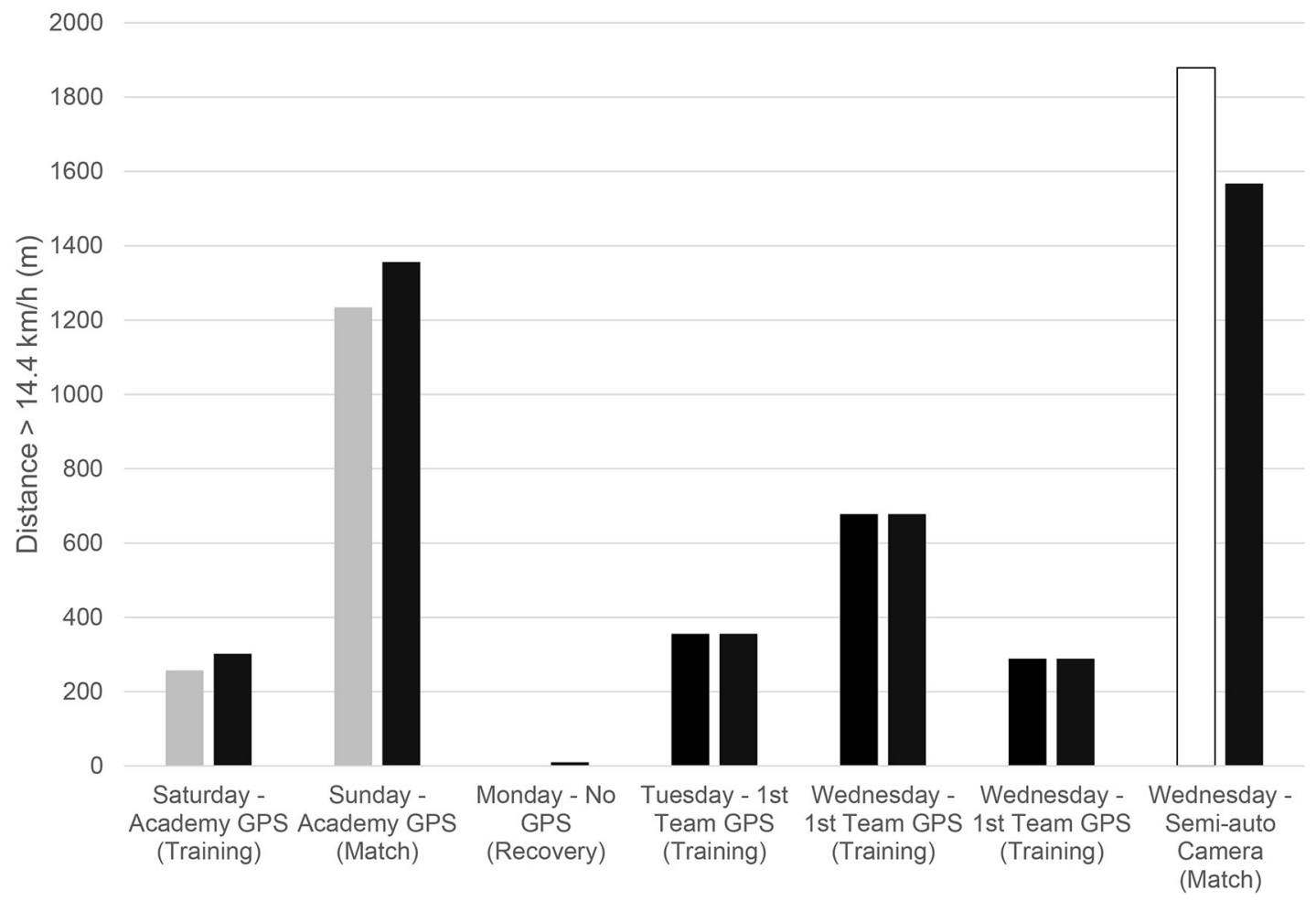

Figure 1 - Distance covered above $14.4 \mathrm{~km} / \mathrm{h}$ during a typical week by a representative academy player in an elite French soccer club. During this specific week, he was tracked using both the academy and 1st Team GPS systems and by a semiautomatic camera system during the match he played with the Pros. Left columns represent raw (as collected) data (total $=4693 \mathrm{~m}$ ). Right columns represent the actual distance estimated via calibration equations that could have been expected to be measured if he had worn consistently the 1st Team GPS system (total $=4558 \mathrm{~m}$ ). Note that while the academy system tends to provide lower estimates than the 1st Team system, the semiautomatic camera system provides greater values. Finally, based on historical drill data, ${ }^{3} 50 \mathrm{~m}$ above $14.4 \mathrm{~km} / \mathrm{h}$ have been added manually for the recovery session (light stride work).

\section{Tracking Accelerations and High-Speed Running: Time to Slow Down?}

\section{Which Variable to Choose?}

Considering that the ideal system does not exist yet, and that all systems have their own advantages and disadvantages, while still all providing more or less the same variables, ${ }^{5}$ it may be more relevant to pick the most useful variables than to focus on the technology per se. To make a substantial impact on the program, it is advised to focus on the variables that are simple enough to be understood and, in turn, used by all practitioners at the club (ranging from the coach to players) and are valid and reliable enough to be trusted when decisions have to be made. When it comes to describing the different types of tracking variables available on the market, the classification of Gray ${ }^{2}$ stands out. He uses 3 distinct levels:

- Level 1: Typical distances covered in different velocity zones ("old school" type of analysis, provided by all technologies). Example: $345 \mathrm{~m}$ run above $19.8 \mathrm{~km} / \mathrm{h}$.

- Level 2: All events related to changes in velocity-accelerations, decelerations, and changes of directions (provided with more or less success by all technologies). Example: 45 accelerations over $3 \mathrm{~m} / \mathrm{s}^{2}$, for a total distance of $233 \mathrm{~m}$.

- Level 3: All events derived from the inertial sensors/accelerometers (microtechnology only, so unavailable with camera-derived systems). Examples: 17 impacts above $6 \mathrm{~g}$, PlayerLoad of 456
$\mathrm{AU}$, stride variables (force load on the ground, contact times), stride imbalances ( $4 \%$ reduced impulse force on the right leg). ${ }^{8,9}$

In a recent meta-analysis, ${ }^{1}$ total distance, high-speed running, acceleration/deceleration patterns, and metabolic power were the variables that were rated as the most important for elite team practitioners. Total distance is generally used as a proxy of overall training volume. High-speed-running distance (also called stride work, which involves high activation of hamstring muscles) and acceleration/deceleration patterns (also called mechanical work, involving tight muscles) are believed to be the most important variables to be tracked since they refer to a more neuromuscular-oriented type of load, which is likely more linked with injury risk. ${ }^{3,10,11}$ Metabolic power is a hybrid measure based on both level 1 and level 2 types of variables and is meant to provide a good estimate of the overall cost of high-intensity actions while combining the actual cost of highspeed (level 1) and accelerated (level 2) running. ${ }^{12}$ Unfortunately, however, practitioners are left with a difficult dilemma when selecting their variables, since their validity and reliability is likely inversely related to their importance in terms of load monitoring, that is, high-speed running, acceleration/deceleration work, and metabolic power being the least valid and reliable variables. ${ }^{1,13}$ In other words, the variables that are believed to be best are likely the least useful. ${ }^{2}$ This does not mean that those variables should not be monitored but, rather, suggests that greater care should be taken when interpreting their differences or changes (ie, defining a larger, more conservative smallest worthwhile difference/change). ${ }^{14}$ Also, a variable with a 
limited validity can still be useful if it is clearly sensitive to training or fatigue (which refers to a large signal-to-noise ratio). ${ }^{15}$

It is now very clear that activity patterns of players is more dependent on tactical issues (rules, coaches' interventions, score line) than influenced by their current fitness status. ${ }^{16}$ For this reason, locomotor-related variables (levels 1 and 2) may not be suitable for the monitoring of training status; in contrast, level 3 types of variables can be collected irrespective of players' activity on the pitch, and have greater potential for the monitoring of fitness and fatigue. ${ }^{8}$ It is, however, worth noting that when level 3 variables are not available (using semiautomatic cameras or some GPS brands that do not provide such variables), some relevant information can still be gained with level 1 and level 2 variables_-but only in the very specific context of highly standardized drills. ${ }^{17}$ Figure 2 shows how a player's readiness to perform could be assessed during congested fixtures using simple running performance indicators during highly standardized drills, that is, during match-simulation drills the days before matches (in the context of similar small-sided-game formats, number of players, and drill duration). Results show that the longer the between-matches recovery period, the greater the match simulation activity, which mirrors the physiological and performance recovery processes in the 2 to 3 days after matches. ${ }^{18}$

\section{Limitations of Common Tracking Variables, With Special Reference to GPS Systems}

In addition to potential validity and reliability issues, there are other important limitations to consider when using some of these tracking variables, including

- Accelerations values are directly related to the time window (duration over which the acceleration is measured, in general between 0.2 and $0.8 \mathrm{~s}$, Figure 3 ) and the signal-filtering technique used. ${ }^{13}$ There is unfortunately no consensus on the
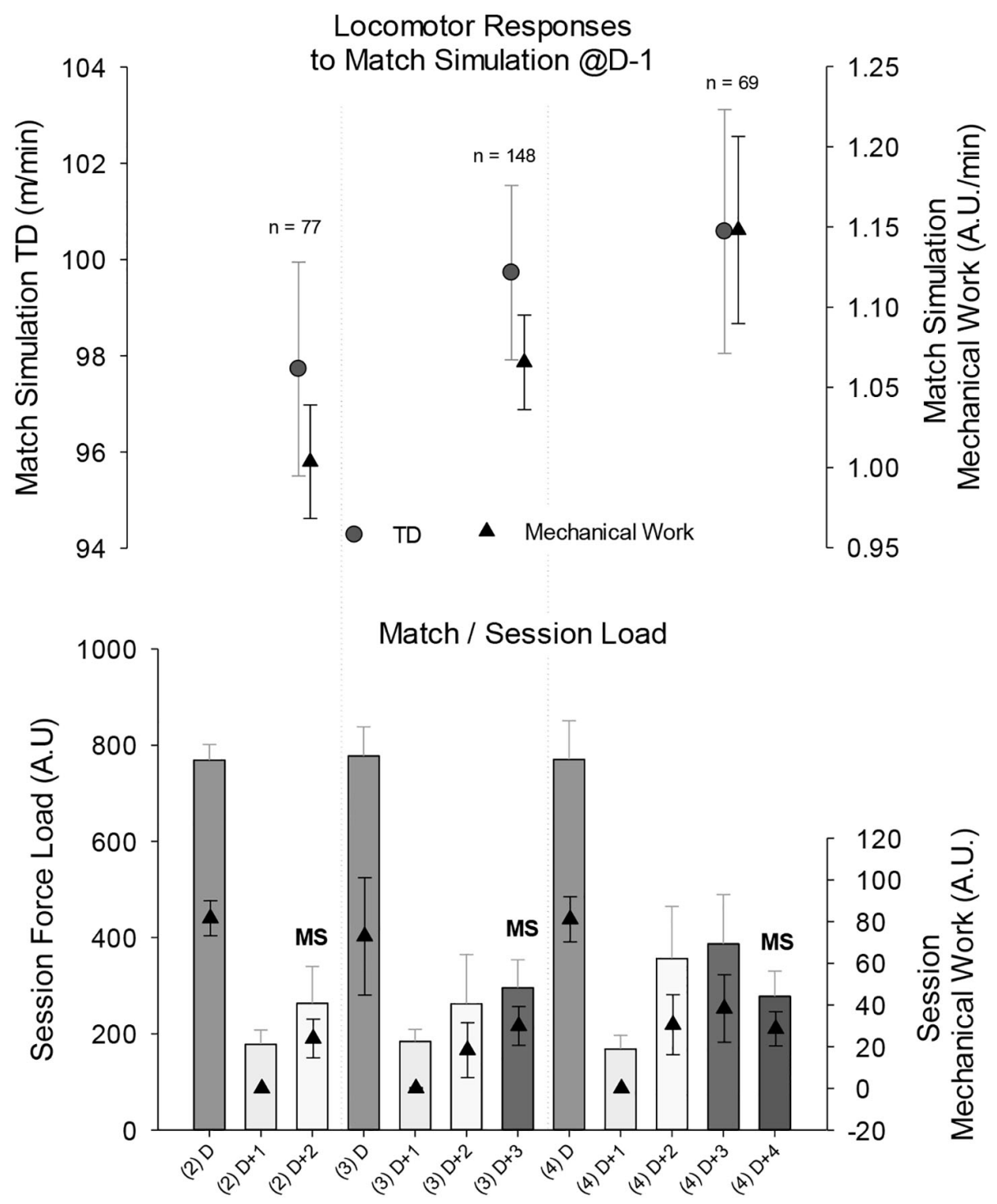

Figure 2 - Upper panel: locomotor responses (total distance covered [circles] and mechanical work [triangles] per minute) during match simulation drills (MS) the day before a match (D-1), as a function of the number of days between 2 consecutive matches in professional soccer players from an elite French team. Lower panel: sessions/matches force load (bars) and mechanical work (triangles) as a function of the number of days between 2 consecutive matches. Match simulations: 9 versus 9 players ( 2 goalkeepers), $50 \times 55 \mathrm{~m}$, free touches, $2 \times 8$ minutes. Mechanical work is a variable provided by the ADI analyzer ${ }^{3,8}$ as a compound measure of accelerations, decelerations, and changes of directions. 


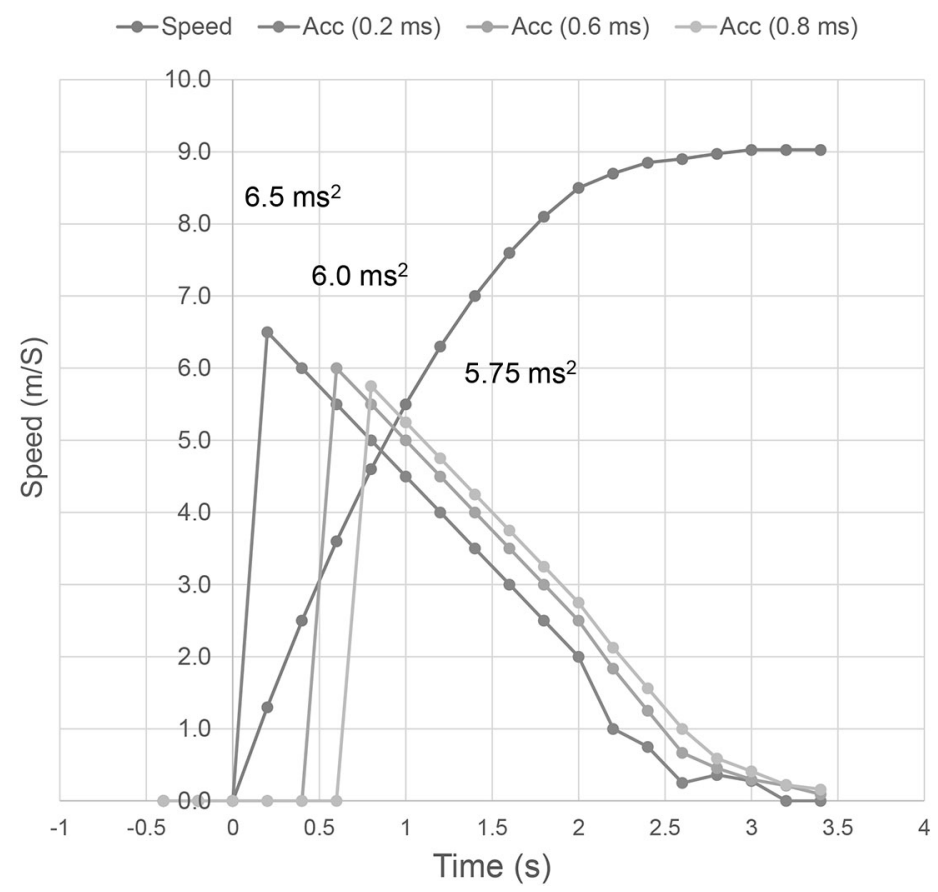

Figure 3 - Maximal acceleration calculated during a maximal 20-m sprint, as a function of the windows used to derive acceleration $(0.2,0.6$, or $0.8 \mathrm{~s}$ ). The shorter the window, the greater the acceleration value. There are today some discrepancies between brands and practices, and there is no consensus on the optimal window duration to use. This remains an important limitation when it comes to monitoring players' "true" acceleration capacities.

optimal time window and filter to use. A simple and relevant alternative to the use of arbitrary time windows could be to report acceleration over a meter (ie, the base unit of length in the International System of Units). ${ }^{19}$

- Companies often update their data processing technique (software or unit chipset updates), which can create large differences in data output. ${ }^{7}$ It is therefore almost impossible to hold historical databases, unless you never update your system.

- The number of GPS satellites available and their spread in the sky (geometric dilution of precision (GDOP), with the greater the spread of the satellites, the better the signal quality) in response to variations in time of day, location on earth or possible infrastructures (stadium roofs may cause partial blockage); unfortunately, however, activity reports do not readily provide this detailed information, leading to a potentially unclear representation in their readings.

- There are large differences in GPS distance recorded when using the Doppler technique versus local coordinates-while the Doppler tends to be the preferred method today, some inconsistencies remain between brands.

- The validity of accelerations and distance into speed zones is acceleration ${ }^{20}$ and speed ${ }^{5}$ dependent; that is, their validity decreases as the acceleration and speed increase. So to speak, variables of most importance are likely the least useful.

- Increased sampling frequency does not always translate into better precision and validity. ${ }^{5}$
- There are large between-units variations (up to 50\%), even between units from the same brands. ${ }^{7}$ The direct consequence is that players should always use the same unit, and we should always remain cautious when comparing different players' data (and use larger magnitude thresholds for meaningful differences ${ }^{14}$ ).

\section{Metabolic Power: Powerful Enough to Drive Ferraris?}

Since Osgnach et al in $2010^{12}$ showed the potential application of the metabolic-power concept ${ }^{21}$ for load monitoring in soccer, the interest for this variable has grown exponentially and is now used across many other team sports. ${ }^{22-25}$ In fact, most GPS brands now offer the ability to monitor players' metabolic power, and a majority of practitioners use this variable when reporting. ${ }^{1}$ While we ${ }^{26}$ have been the first to be excited about the potential of this monitoring approach, we have since reconsidered our opinion and now question its usefulness in the field to monitor elite players (ie, "Ferraris"). This is essentially related to recent research findings questioning the validity of this construct in the context of team-sport-specific movements and the fact that it is only an incomplete metabolic measure of internal load and a too broad marker of external load.

\section{What Are We Measuring in the End?}

It has now been shown by 4 distinct and independent research groups that locomotor-related metabolic power assessed via either GPS or local positioning system $\left(\mathrm{P}_{\mathrm{GPS}}\right)$ differs largely from the true metabolic demands as assessed via indirect calorimetry ( $\mathrm{VO}_{2}$ measures, $\left.\mathrm{P}_{\mathrm{VO} 2}\right)$. $\mathrm{P}_{\mathrm{GPS}}$ was actually reported to be very largely greater than $\mathrm{P}_{\mathrm{VO} 2}$ during walking ${ }^{27}$ but very largely lower during shuttle runs at low speed ${ }^{28}$ and during soccer-,${ }^{26}$ rugby-,${ }^{29}$ or team-sport-specific ${ }^{27}$ circuits. While some may see the consistency of such conclusions as a kind of consensus, Osgnach et $\mathrm{al}^{30}$ suggested that some methodological errors may explain the underestimation of $\mathrm{P}_{\mathrm{GPS}}$ reported. ${ }^{26-29}$ Among others, they attributed our discordant results to the inclusion of resting $\mathrm{VO}_{2}$ when calculating $\mathrm{P}_{\mathrm{VO} 2}$ (while we have in fact used net $\mathrm{VO}_{2}$, as clearly written in Buchheit et al, ${ }^{26}$ p. 1151, second paragraph), the impact of nonlocomotor actions on $\mathrm{P}_{\mathrm{VO} 2}$ (while team sports often include intense but static movements that logically increase systemic energy expenditure $\left[\mathrm{P}_{\mathrm{VO} 2}\right]$ independently of locomotor movements $\left.\left.\left[\mathrm{P}_{\mathrm{GPS}}\right]\right)^{31}\right)$, an underestimation of the anaerobic contribution to $\mathrm{P}_{\mathrm{VO} 2}$ (while if we had better accounted for the entire anaerobic contribution to $\mathrm{P}_{\mathrm{VO} 2}$, the $\mathrm{P}_{\mathrm{GPS}}$ underestimation that we reported would have been even greater, not smaller ${ }^{31}$ ), and our 4-Hz GPS sampling frequency (while the other researchers have all reported the same underestimation using higher sampling frequencies ie, $500,{ }^{28} 10,{ }^{29}$ and $5^{27} \mathrm{~Hz}$ ). Note also that we have shown that sampling frequency per se was not the most important factor when it comes to precision and validity. ${ }^{5}$ Detailed and illustrated answers to these 4 points have been offered elsewhere ${ }^{31}$ and confirm the limitations of $\mathrm{P}_{\mathrm{GPS}}$ in the context of interest, ie, monitoring teamsport-specific efforts with the available technology on the market.

\section{Adding Value to Load-Monitoring Systems?}

Considering that the agreement between $\mathrm{P}_{\mathrm{GPS}}$ and $\mathrm{P}_{\mathrm{VO} 2}$ has only been shown to be acceptable during continuous and linear jog and runs (but neither during walking nor intermittent changes of direction runs), ${ }^{27}$ the metabolic underestimation consistently reported ${ }^{26-29}$ may be related to the fact that the current equation initially developed for maximal and linear sprint acceleration ${ }^{21}$ may not be well suited for team-sport-specific running patterns (eg, including 
rest, irregular step frequency and stride length, turns, upper body muscle activity, static movements). ${ }^{26}$ Additionally, if $\mathrm{P}_{\mathrm{GPS}}$ was to only reflect locomotor-related metabolic activity (as opposed to a systemic measure such as $\mathrm{P}_{\mathrm{VO} 2}$ ), what would be the value of such an impartial measure of metabolic load? This is at odds with all attempts to use $\mathrm{P}_{\mathrm{GPS}}$ outputs for overall load monitoring or nutritional (posttraining/match recovery) guidelines. ${ }^{25}$ Taken together, these limitations suggest that the value of $\mathrm{P}_{\mathrm{GPS}}$ per se to monitor training load in team sports may be questionable. Its usefulness may also be limited with respect to practitioners' expectations in the field. In fact, practitioners are likely seeking

- Overall estimates of internal load, which are in our views satisfactorily assessed through HR and RPE measures ${ }^{1}$ - information on the metabolic load of exclusively locomotor-related actions as with $\mathrm{P}_{\mathrm{GPS}}$ may not be comprehensive enough.

- Precise measures of external load, which directly relate to specific mechanical constraints on players' anatomy, which, in turn target specific muscle groups. This has direct implications for training, recovery, and injury risk. However:

- $\mathrm{P}_{\mathrm{GPS}}$ is clearly dissociated from actual muscle activation, as exemplified by very large variations in the $\mathrm{P}_{\mathrm{GPS}} / \mathrm{EMG}$ ratio during accelerated vs. decelerated running. ${ }^{19}$

- $\mathrm{P}_{\mathrm{GPS}}$, if it was to be used as a global marker of mechanical work (combining level 1 and 2 types of variables), would not decipher the underlying mechanisms of the load-we rather use distance while accelerating, decelerating and while running at high-speed since those variables may relate directly to the load of specific muscle groups.

- Injuries are most generally related to inappropriate volumes of accelerations ${ }^{10}$ or high-speed running ${ }^{11}$; there is in contrast little evidence to suggest that spikes in overall energy consumption per se may play a role in injury etiology.

\section{Where Do We Go From Here?}

We wished to finish with the introduction of two innovative and promising types of variables (Athletic Data Innovation analyzer [ADI], Sydney, NSW, Australia), ${ }^{3,8}$ not cited in the meta-analysis, ${ }^{1}$ that represent clear advances in terms of external load and fatigue monitoring. One of the greatest benefits of these variables is that, in contrast to Level 1 and 2 variables that are pacing- or playerengagement-dependent, players do not need to perform maximally for these latter variables to be useful. From there, every training session becomes an assessment.

- Force load (FL). With the ADI analyzer, ${ }^{3,8}$ Force load refers to the sum of estimated ground-reaction forces during all foot impacts, assessed via the accelerometer-derived magnitude vector. In comparison with Player/Body Load ${ }^{9}$ (whole-body load based on overall accelerometer activity) or total distance, FL reflects only locomotor-related impacts and provides better estimates of overall foot work and impulses, especially when the sessions include static movements and little displacements (eg, toros, football tennis, free kicks).

a. In relation to the actual distance covered (TD/FL) or the average velocity (V/FL) during a given drill, force load can be used for at least 2 purposes: to assess neuromuscular/running efficiency (greater the ratio, better the efficiency) ${ }^{32}$ and to provide new insights into the mechanical demands of on-field running drills, such as the main direction of force application (ie, large vs small ratios standing for more horizontal vs more vertical forces applications, respectively, Figure 4). As shown in Figure 4 , when comparing for the first time the mechanical demands of different 15-m-sprint conditions, the V/FL ratio decreases with the increased need for horizontal-force production.

b. Force load can also be compared between right and left legs, and stride imbalance can be tracked during any type of locomotive actions (eg, specifically while accelerating vs running at high speed, which likely relates to the use and potential weaknesses of different muscle groups). ${ }^{8}$ This is obviously very relevant during the return-to-play period (Figure 5) and to track eventual muscle-strength deficits in yet healthy players. ${ }^{33}$
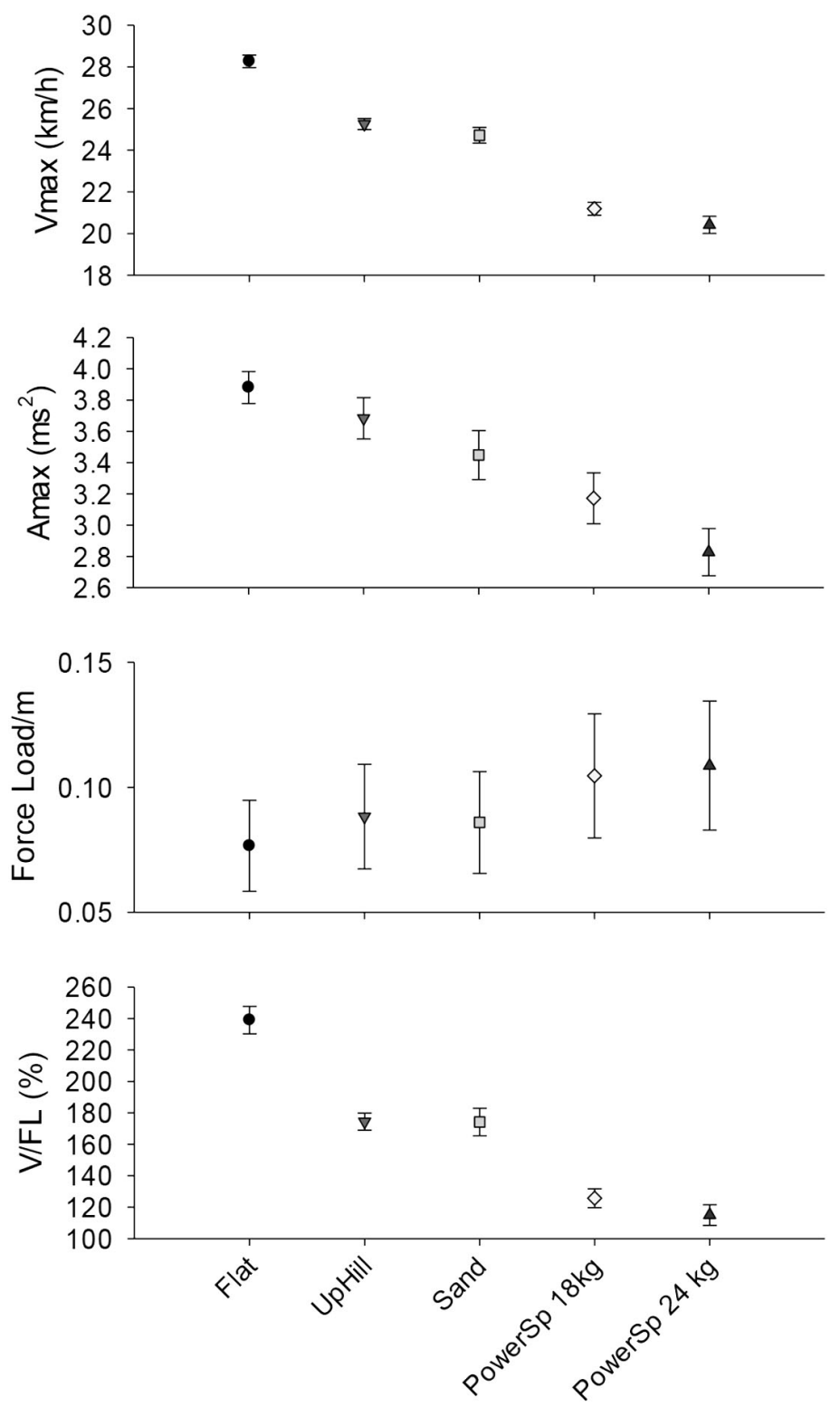

Figure 4 - Maximal velocity (Vmax), maximal acceleration (Amax), force load per meter (force load/m), and velocity:force-load ratio (V/FL) during maximal $15-\mathrm{m}$ sprints performed either on flat terrain on a football pitch (flat), a 4\%-grade uphill slope (uphill, same grass as the pitch), on sand (wearing wind surfing shoes), pulling the equivalent of 18 and $24 \mathrm{~kg}$ using the Power Sprint machine. The data were collected in 10 professional soccer players during the same training session (each data point represents the average of 3 trials per condition with $90 \%$ confidence intervals). 


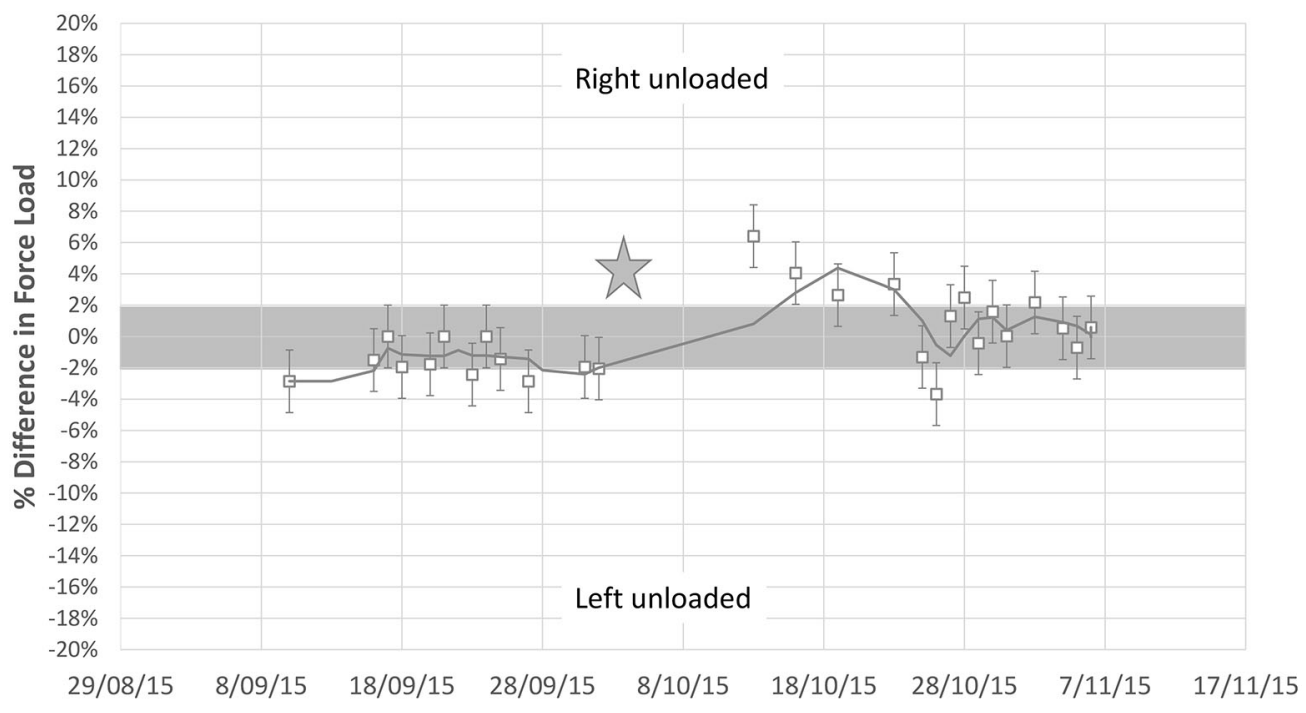

Figure 5 - Example of force-load symmetry in a player during his return to play period after a right ankle sprain. The symmetry (with errors bars standing for typical error of measurement $\left.{ }^{8}\right)$ is calculated from the force load of all foot impacts during all accelerated running phases $\left(>2 \mathrm{~m} / \mathrm{s}^{2}\right)$ of each session. The star represents the date of the injury. In the absence of a clear value for the optimal smallest worthwhile change, the shaded area was defined using the typical error of measurement. Continuous line: rolling average over 3 days.

- Stride characteristics (contact and flight time, also calculated from accelerometer data). From these simple variables it is now possible to accurately calculate vertical stiffness, ${ }^{8}$ which has been shown to decrease substantially with neuromuscular fatigue. ${ }^{34,35}$ The constant monitoring of stride characteristics (or at least ground impact-related lower-leg vertical activity ${ }^{36}$ ), more preferably during standardized running bouts, ${ }^{32}$ offers a new alternative to the V:FL ratio and provides new perspectives for the field monitoring of neuromuscular status. Another very practical aspect of the present stride variables is that accelerometers can be used indoor (ie, no GPS signal needed), allowing their use for almost every type of running-based sports (eg, basketball, handball).

\section{Conclusion}

Monitoring players' overall external training load is only possible through the integration of the different technologies used in combination in most clubs (eg, GPS and semiautomatic camera tracking for training and matches, respectively). ${ }^{5}$ Until new solutions are developed, the use of club-specific calibration equations is probably the "lesser of all evils," but practitioners would still be faced with the downside of technology and/or computing advances (eg, firmware or software updates), ${ }^{7}$ which ultimately compromises long-term monitoring plans. When it comes to monitoring training status, level 1 and 2 tracking data may only be worthy in the context of highly standardized drills. ${ }^{17}$ In contrast, pacing-free level 3 variables (eg, stride parameters, force $\operatorname{load}^{8}$ ) may offer a greater sensitivity, although more research is still warranted to confirm this hypothesis. Considering that the perfect tracking system still does not exist, ${ }^{5}$ and given the numerous limitations of the most advocated variables (accelerations, metabolic power), the foundations of a successful player-monitoring system should focus on the manner in which practitioners collect their own tracking data, their understanding of the limitations of each variable, and how they report and use all this information, rather than in the technology and the variables per se. Furthermore, the validity and reliability and the practical interpretation of tracking variables should never be overlooked; the most useful tracking variables are very likely those that can be understood and in turn, used by all practitioners at the club. Our opinion is that before adopting new pieces of technology or variables, practitioners should assess their usefulness first, to ensure worthwhile incorporation into their program. Overall, the decision to use any tracking technology or new innovative variable should always be considered with a cost/ benefit approach (ie, cost, ease of use, portability, and manpower/ ability to affect the training program). Technology should be preferred over simpler methods only when unique and important information can be obtained (eg, the percentage of maximal speed reached during a session, which may directly affect injury risk, ${ }^{37}$ cannot be assessed via session RPE). Anecdotally, very successful coaches still make most of their decisions based on information as simple as accumulated training and playing time! We are nevertheless confident that in the future, with the advances in terms of micro technology, the development of new tracking variables and appropriate sport-science support, ${ }^{38}$ even those coaches would start to see the glass as half full.

\section{References}

1. Akenhead R, Nassis GP. Training load and player monitoring in highlevel football: current practice and perceptions. Int J Sports Physiol Perform. 2016;11:587-593. PubMed doi:10.1123/ijspp.2015-0331

2. Buchheit M. Player tracking technology: what if we were all wrong? In: Monitoring Athlete Training Loads-The Hows and Whys. Presentation at: 2nd Aspire Sport Science Conference; February 2016; Doha, Qatar. Available at: https://vimeo.com/159904163.

3. Colby M, Dawson B, Heasman J, Rogalski B, Gabbett TJ. Training and game loads and injury risk in elite Australian footballers [published online ahead of print April 7, 2014]. J Strength Cond Res. 2014. PubMed doi:10.1519/JSC.0000000000000362

4. Gabbett TJ. The training-injury prevention paradox: should athletes be training smarter and harder? Br J Sports Med. 2016;50:273-280. PubMed doi:10.1136/bjsports-2015-095788 
5. Buchheit M, Allen A, Poon TK, Modonutti M, Gregson W, Di Salvo V. Integrating different tracking systems in football: multiple camera semi-automatic system, local position measurement and GPS technologies. J Sports Sci. 2014;32(20):1844-1857. PubMed doi:10.10 80/02640414.2014.942687

6. Anderson L, Orme P, Di Michele R, et al. Quantification of training load during one-, two- and three-game week schedules in professional soccer players from the English Premier League: implications for carbohydrate periodisation. J Sports Sci. 2016;34:1250-1259. PubMed doi:10.1080/02640414.2015.1106574

7. Buchheit M, Al Haddad H, Simpson BM, et al. Monitoring accelerations with GPS in football: time to slow down? Int J Sports Physiol Perform. 2014;9:442-445. PubMed doi:10.1123/ijspp.2013-0187

8. Buchheit M, Gray A, Morin JB. Assessing stride variables and vertical stiffness with GPS-embedded accelerometers: preliminary insights for the monitoring of neuromuscular fatigue on the field. $J$ Sports Sci Med. 2015;14:698-701. PubMed

9. Barrett S, Midgley A, Lovell R. PlayerLoad: reliability, convergent validity, and influence of unit position during treadmill running. Int J Sports Physiol Perform. 2014;9:945-952. PubMed doi:10.1123/ ijspp.2013-0418

10. Bowen L, Gross AS, Gimpel M, Li FX. Accumulated workloads and the acute:chronic workload ratio relate to injury risk in elite youth football players. Br J Sports Med. 2017;51(5):452-459. PubMed doi:10.1136/bjsports-2015-095820

11. Duhig S, Shield AJ, Opar D, Gabbett TJ, Ferguson C, Williams M. Effect of high-speed running on hamstring strain injury risk. Br J Sports Med. 2016;50(24):1536-1540. PubMed doi:10.1136/ bjsports-2015-095679

12. Osgnach C, Poser S, Bernardini R, Rinaldo R, di Prampero PE. Energy cost and metabolic power in elite soccer: a new match analysis approach. Med Sci Sports Exerc. 2010;42:170-178. PubMed doi:10.1249/MSS.0b013e3181ae5cfd

13. Haugen T, Buchheit M. Sprint running performance monitoring: methodological and practical considerations. Sports Med. 2016;46(5):641-656. PubMed

14. Buchheit M. The numbers will love you back in return-I promise. Int J Sports Physiol Perform. 2016;11:551-554. PubMed doi:10.1123/ ijspp.2016-0214

15. Buchheit M. Monitoring training status with HR measures: do all roads lead to Rome? Front Physiol. 2014;5:73. PubMed

16. Carling C. Interpreting physical performance in professional soccer match-play: should we be more pragmatic in our approach? Sports Med. 2013;43:655-663. PubMed doi:10.1007/s40279-013-0055-8

17. Buchheit M, Racinais S, Bilsborough JC, et al. Monitoring fitness, fatigue and running performance during a pre-season training camp in elite football players. J Sci Med Sport. 2013;16:550-555. PubMed doi:10.1016/j.jsams.2012.12.003

18. Nédeléc M, McCall A, Carling C, Legall F, Berthoin S, Dupont G. Recovery in soccer: part I-post-match fatigue and time course of recovery. Sports Med. 2012;42:997-1015. PubMed

19. Hader K, Mendez-Villanueva A, Palazzi D, Ahmaidi S, Buchheit M. Metabolic power requirement of change of direction speed in young soccer players: not all is what it seems. PLoS One. 2016;11:e0149839. PubMed doi:10.1371/journal.pone.0149839

20. Akenhead R, French D, Thompson KG, Hayes PR. The acceleration dependent validity and reliability of $10 \mathrm{~Hz}$ GPS. J Sci Med Sport. 2014;17:562-566. PubMed doi:10.1016/j.jsams.2013.08.005

21. di Prampero PE, Fusi S, Sepulcri L, Morin JB, Belli A, Antonutto G. Sprint running: a new energetic approach. J Exp Biol. 2005;208:2809_ 2816. PubMed doi:10.1242/jeb.01700
22. Cummins C, Gray A, Shorter K, Halaki M, Orr R. Energetic and metabolic power demands of National Rugby League match-play. Int J Sports Med. 2016;37:552-558. PubMed doi:10.1055/s-0042-101795

23. Malone S, Solan B, Collins K, Doran D. The metabolic power and energetic demands of elite Gaelic football match play [published online ahead of print March 31, 2016]. J Sports Med Phys Fitness. PubMed

24. Vescovi JD. Locomotor, heart-rate, and metabolic power characteristics of youth women's field hockey: Female Athletes in Motion (FAiM) study. Res Q Exerc Sport. 2016;87:68-77. PubMed doi:10.1080/0270 1367.2015.1124972

25. Coutts AJ, Kempton T, Sullivan C, Bilsborough J, Cordy J, Rampinini E. Metabolic power and energetic costs of professional Australian football match-play. J Sci Med Sport. 2015;18:219-224. PubMed doi:10.1016/j. jsams.2014.02.003

26. Buchheit M, Manouvrier C, Cassirame J, Morin JB. Monitoring locomotor load in soccer: is metabolic power, powerful? Int J Sports Med. 2015;36:1149-1155. PubMed doi:10.1055/s-0035-1555927

27. Brown DM, Dwyer DB, Robertson SJ, Gastin PB. Metabolic power method: underestimation of energy expenditure in field-sport movements using a global positioning system tracking system. Int J Sports Physiol Perform. 2016;11(8):1067-1073. doi:10.1123/ijspp.2016-0021

28. Stevens TG, de Ruiter CJ, van Maurik D, van Lierop CJ, Savelsbergh GJ, Beek PJ. Measured and estimated energy cost of constant and shuttle running in soccer players. Med Sci Sports Exerc. 2015;47:1219-1224. PubMed doi:10.1249/MSS.0000000000000515

29. Highton J, Mullen T, Norris J, Oxendale C, Twist C. The unsuitability of energy expenditure derived from microtechnology for assessing internal load in collision-based activities. Int J Sports Physiol Perform. 2017;12(2):264-267. PubMed doi:10.1123/ijspp.2016-0069

30. Osgnach C, Paolini E, Roberti V, Vettor M, di Prampero PE. Metabolic power and oxygen consumption in team sports: a brief response to Buchheit et al. Int J Sports Med. 2016;37:77-81. PubMed doi:10.1055/s-0035-1569321

31. Buchheit M. Metabolic power: powerful enough to drive Ferraris? 2016. https://martin-buchheit.net/2016/12/01/metabolic-powerpowerful-enough-to-drive-ferraris/

32. Buchheit M, Cholley Y, Lambert P. Psychometric and physiological responses to a preseason competitive camp in the heat with a 6-hour time difference in elite soccer players. Int J Sports Physiol Perform. 2016;11:176-181. PubMed doi:10.1123/ijspp.2015-0135

33. Fousekis K, Tsepis E, Poulmedis P, Athanasopoulos S, Vagenas G. Intrinsic risk factors of non-contact quadriceps and hamstring strains in soccer: a prospective study of 100 professional players. Br J Sports Med. 2011;45:709-714. PubMed doi:10.1136/bjsm.2010.077560

34. Morin JB, Jeannin T, Chevallier B, Belli A. Spring-mass model characteristics during sprint running: correlation with performance and fatigue-induced changes. Int J Sports Med. 2006;27:158-165. PubMed doi:10.1055/s-2005-837569

35. Girard O, Micallef JP, Millet GP. Changes in spring-mass model characteristics during repeated running sprints. Eur J Appl Physiol. 2011;111:125-134. PubMed doi:10.1007/s00421-010-1638-9

36. Cormack SJ, Mooney MG, Morgan W, McGuigan MR. Influence of neuromuscular fatigue on accelerometer load in elite Australian football players. Int J Sports Physiol Perform. 2013;8:373-378. PubMed doi:10.1123/ijspp.8.4.373

37. Malone S, Roe M, Doran DA, Gabbett TJ, Collins K. High chronic training loads and exposure to bouts of maximal velocity running reduce injury risk in elite Gaelic football. J Sci Med Sport. 2017;20(3):250-254. PubMed doi:10.1016/j.jsams.2016.08.005

38. Buchheit M. Chasing the 0.2. Int J Sports Physiol Perform. 2016;11:417418. PubMed doi:10.1123/ijspp.2016-0220 